LAS, NARRACIONES CORTAS

DE ÁLVARO CUNQUEIRO

\title{
Ángel Basanta
}

Asociación Española de Críticos Literarios

doi:10.17075/mucnoc.2014.021 

Forcadela, M. / T. López / D. Vilavedra (coords.) (2014): Mil e un cunqueiros. Novas olladas para un centenario, Santiago de Compostela, Consello da Cultura Galega. doi:10.17075/mucnoc.2014. pp. 437-446

Además de sus tres novelas en gallego, Merlin e familia (1955), As crónicas do Sochantre (1956), que fue Premio de la Crítica en 1959, y Se o vello Sinbad volvese ás illas (1961), a las cuales hay que añadir otras escritas en castellano, como Las mocedades de Ulises (1960), Un hombre que se parecía a Orestes (1969), que ganó el Premio Nadal, Vida y fugas de Fanto Fantini (1972) y El año del cometa (1974), entre otras, hay en la obra narrativa de Álvaro Cunqueiro tres libros importantes de narraciones cortas, concebidas en artístico maridaje entre la semblanza, el cuento y la anécdota. Son tres volúmenes que componen una singular trilogía, supuestamente menor en la literatura cunqueiriana, pero del más alto mérito literario: Escola de menciñeiros (1961), Xente de aqui e de acolá (1971) y Os outros feirantes (1979). A los cuales aún se podría añadir Tesouros novos e vellos (1964), deliciosa recreación de tesoros encantados, una de las materias preferidas del autor, quien lo adoptó como tema de su discurso de ingreso en la Real Academia Gallega en 1961.

Esta trilogía de relatos, compuesta por semblanzas y retratos de tipos populares, cuentos, anécdotas e historias tomadas de la tradición oral gallega, demuestran que el raro inventor de ficciones fantásticas a partir de mitos orientales y grecolatinos y de leyendas artúricas a partir de la materia de Bretaña supo completar su extraordinaria erudición y vasta cultura, asimiladas con la lectura de muchos libros, viviendo muy apegado a la tierra gallega. Si en sus novelas nos maravilla con sus fantásticas adaptaciones de Sinbad y de Ulises a la ría de Vigo o del mago Merlín a las Tierras de Miranda, que ocupan el territorio real de mi municipio de Pastoriza (entre Mondoñedo y Meira), en las narraciones de signo antropológico que componen estos tres libros, el autor de Mondoñedo deja testimonio fehaciente de su interés e inagotable curiosidad por cuanto sucedía en la vida diaria de las gentes de su tierra.

De aquellos barros de la existencia cotidiana en la Galicia rural, supo elevarse a las más altas cotas literarias, superando siempre el peligro del mero costumbrismo en favor del entendimiento antropológico del alma gallega y su proyección universal. Más que nunca se cumple aquí aquella idea del portugués trasmontano 
Miguel Torga, según la cual lo universal es lo local sin fronteras. Y, para comprobarlo, y aún completarlo, pues salimos de la Galicia rural y nos acercamos a los textos cunqueirianos de naturaleza marina, bastará con una cita de Fábulas y leyendas de la mar, otro libro suyo en el que se han reunido textos con historias de ambientación marinera inspirados en la muy cercana «mariña» lucense: «El faro que yo más amé fue el primero que vi de niño en las tardes de verano, desde el mar de Foz: era el faro de Tapia de Casariego, al este, en el mar de las Asturias de Oviedo, acariciando cielo y mar. Era como un dios"1.

En su conjunto, la trilogía de la Galicia rural constituye una peculiar comedia humana gallega, formada por labradores, artesanos, capadores, curanderos, emigrantes, mareantes y toda una variopinta fauna de individuos más o menos extravagantes de la provincia de Lugo que Cunqueiro retrata y recrea transfigurándolos en joyas literarias. He aquí, pues, una excelente representación de la medicina popular, encarnada en la sabiduría y habilidad de los menciñeiros gallegos y toda una galería de tipos populares y de historias que el autor conoce por la tradición oral, aprendida desde niño en las tardes y noches narradas en la farmacia de su padre y en la casa familiar de Mondońedo y también por descubrimiento personal del medio siendo ya un adulto que gustaba de chapuzarse en el diálogo directo con las gentes de las aldeas vecinas.

La maravilla de tan simpáticas narraciones nace de su encanto armonizador entre lo más enxebre de su punto de partida en una visión intuitiva de la realidad cotidiana y la imaginación creadora del autor para transformar aquellos materiales tan rústicos en la invención de historias preńadas de mentiras verdaderas, donde realidad y ficción se rigen por el mismo código, sin que la razón pueda establecer una separación excluyente, pues la magia también forma parte de aquella realidad. Es verdad que estas narraciones constituyen lo más representativo del realismo en la literatura de Cunqueiro. Pero, en este gran conocedor de la Galicia real, que también es su mayor fabulador, realidad y fantasía nunca son mundos excluyentes. Sus novelas más fantásticas resultan verosímiles y creíbles porque su estrategia narrativa opera siempre con genuinos procedimientos realistas, como bien ha estudiado Anxo Tarrío en su libro Álvaro Cunqueiro ou os disfraces da

1 Cfr. Álvaro Cunqueiro: Fábulas y leyendas de la mar. [Edición de Néstor Luján]. Tusquets, Barcelona, 1982, p. 141. 
melancolía ${ }^{2}$ Y, en artística compensación, se produce un fenómeno de signo contrario en los relatos de su trilogía más realista: sus narraciones arrancan de la realidad cotidiana para convertirse en indagación antropológica sobre el hombre gallego, alimentada por una sutil combinación de ruralismo poético, humorismo lúdico y fantasía naturalizada en la vida cotidiana, con lo cual este impresionante abanico de tipos insólitos con capacidades sorprendentes se transforma en una asombrosa fauna popular igualmente representativa de la Galicia real y la mágica.

La autenticidad de las narraciones de los tres libros nace de la extracción de sus personajes a partir de modelos reconocibles en la realidad antropológica gallega, de la localización de sus historias en coordenadas espaciales y temporales muy cercanas y verificables en la realidad inmediata y también de su fidelidad a los modelos narrativos de la tradición oral gallega, muy fértil en los años de formación del escritor y jamás abandonada en la infinita curiosidad del creador. Literariamente, esto último es lo más importante, por lo que vale la pena detenerse algo más en ello para comprender el proceso genético de sus invenciones.

De Cunqueiro y su apariencia de hombre despistado decía D. García-Sabell que, cuando Álvaro llegaba a sus reuniones de amigos en Santiago de Compostela, éste parecía venir de muy lejos y por ello tardaba en darse cuenta de la realidad. Lo escribió en el prólogo de Merlín e familia, refiriéndose a su amigo mindoniense como un hombre distendido y bonancible: «Siempre parece, cuando nos habla o simplemente nos mira, que acaba de descubrir en nosotros a un ser de otra especie al que es necesario tratar con delicadeza y tino especiales. Lo que pasa es que él acaba de llegar, en ese momento, de un viaje lejano e indescriptible y, al principio, no hace pie en el suelo de todos los días. Por eso él es, sobre todo, un testigo. Y cuando nos habla y nos cuenta un suceso absolutamente inverosímil no miente, testifica. El que miente comienza por no creer en lo que él dice. Y Cunqueiro es el más importante creedor que tenemos en Galicia. Por eso le resulta tan difícil percibir con claridad donde remata lo empíreo de la fantasía y comienza lo ordinario de la objetividad. Justamente, por ser un inmenso creedor es un estupendo creador ${ }^{3}$.

2 Publicado en Galaxia, Vigo, 1989.

3 Cfr. Domingo García-Sabell: «A grande Regueifa dos curandeiros», prólogo a Escola de menciñeiros. Reproducido en Álvaro Cunqueiro: Obra en galego completa. III. Semblanzas. Galaxia, Vigo, 1983. Pp. 11-52. La cita en pp. 40-41. Cursivas del autor. La traducción es mía. 
Unos quince años más tarde, cuando Cunqueiro publicó el segundo de estos libros, Xente de aqui e de acolá (1971), el gran creedor-creador de ficciones verdaderas contestaba en una carta-prólogo al doctor García-Sabell con estas palabras: «Mi querido Domingo: una vez escribiste de mí que yo llegaba a donde tú estabas, y me acercaba a ti o a los otros, y parecía que yo venía de muy lejos, algo desnortado, y tardaba en darme cuenta de que tú eras tú, y también de donde me hallaba. Cuando tú lo dijiste, algo mucho habrá de verdad en ello. Pues bien, yo podría decirte que venía de estar con estos, de los que cuento en las páginas que siguen. Ahora bien, ¿hubo estos, los hay? Alguien podría contestar, de repente, que no los hubo ni los hay, pues yo los saqué de mi magín. Y el tipo daría por sentenciado el pleito, pero pienso que tú no, y yo tampoco ${ }^{4 \text {. }}$.

En efecto, el problema es mucho más profundo. La imaginación y el talento creador de Cunqueiro moldearon sobre unos tipos reales en la sociedad gallega rural de aquella época unas criaturas de ficción que protagonizan estas joyas literarias. Por eso, el autor insiste, unas líneas después, en su idea de que «estos son retratos de gentes que son de nuestra tribu, y que no podrían ser de otra cualquiera», pues en ellos está la esencia del gallego con «sus varas de medir el mundo, las vueltas de su imaginación, los recovecos de sus sueños y ansias, su calidad intelectual, el gusto de la sorpresa, la ironía que hace de un hombre, en un momento dado, un señor rey, y la humildad, y la sabrosura de la pereza, el dolerse por lo que no hay, y el morir solo con su obsesión, y dejarla en herencia, como un tesoro inencontrable...». Y, al final, el autor quiere que el médico compostelano le ayude a saber si estas criaturas le han salido auténticas, «si esta gente me ha salido parecida en el retrato, y si yo soy o no parte de ella, sońándome narrador de tanta vida y milagro, y si puedo contar todo esto, que casi es de trasmundo, ¿quiérese decir que yo acostumbro a pasar temporadas fuera del mundo, investigando? ¿Investigando el secreto del ser gallego? n.

Como muestra cabal de estas joyas literarias y en el mejor homenaje a su raro inventor, voy a ejemplificar lo dicho con uno de los textos incluido al final de Escola de menciñeiros, en el grupo de Fábula de varia xente, compuesto por cinco

4 Cfr. «Carta que o autor mandóu ao Dr. Domingo García-Sabell cando ordeaba este libro», en Obra en galego completa. III. Semblanzas, cit., pp. 151-153. Cita en p. 151. Traducción mía.

5 Ibidem, pp. 152-153. 
narraciones. Esta es la segunda historia, titulada Melle de Loboso, que a mí me ha servido siempre como la mejor manera de explicar a mis alumnos algo tan difícil de comprender para ellos como es el realismo mágico, que Cunqueiro practicaba por aquí mucho antes de que lo conociéramos en las ficciones de los grandes novelistas y cuentistas hispanoamericanos. Pero antes, quiero aclarar algunas cuestiones acerca de las circunstancias en que tal relato fue escrito porque con el conocimiento del contexto se comprenderá mejor lo contado en el texto. Álvaro Cunqueiro vivió largas temporadas en Mondoñedo. En esas estancias en su ciudad natal, a veces, solía tomar el autobús de línea para llegar hasta el vecino municipio de Abadín. Una vez allí, el escritor era recibido por algún enviado de la familia Melle con una mula para poder atravesar la sierra de A Corda y llegar hasta la casa familiar de aquel cacique rural en Loboso, aldea perteneciente al municipio de Pastoriza, donde Cunqueiro solía pasar algunos días. Y así nació, como tantas otras, esta «fábula de varia gente»:

\section{MELLE DE LOBOSO}

«Un tal Melle, vecino de Loboso, partido judicial de Mondoñedo, decidió cuando ya había cumplido setenta años, aprender a leer y a escribir, y en menos de un mes el maestro tuvo que darlo por útil. A los que le preguntaban a qué venía tomarse aquel trabajo a sus años, contestaba que a lo mejor podía mandar algún recado desde el otro mundo, y entonces siempre sería mejor por escrito que por palabra. Para que no hubiese duda de que era él quien mandaba noticias, dejaría antes de morir una muestra de letra en papel de barba. Y ordenó Melle que cuando muriese, que le metieran en el bolsillo de la chaqueta papel, sobres y lápiz de color.

Loboso es lo más alto de Pastoriza, y hace honor al nombre: montes sombríos, retamales hasta cerca de las casas, huertas pobres, campos en cuesta en los que mal medra el centeno, brezos aislados y el lobo vagante. La gente de Loboso es alta y rubia, y el cabello dorado de las mozas es la única flor en toda aquella soledad.

Murióse Melle, y lo enterraron con recado de escribir como había pedido, y el lápiz de color afilado por las dos puntas, y aun le metieron en el bolsillo una navajita por si quebraba puntas, que apretaba mucho al escribir... Pasó el tiempo 
y no llegaba recado ninguno de Melle y la gente de Loboso íbase olvidando de la ocurrencia. Pasaron dos largos inviernos y dos alegres y pequeños veranos. Un sobrino de Melle, por Pascua, compró en la feria de Meira un par de gallinas, una negra castellana y otra de pescuezo pelado, y al soltarlas en la era les miró el huevo, y esta última venía con él en la punta, tanto que lo puso al día siguiente, a primera hora, y lo cacareó bien. Era un huevo largo, con la cáscara ennegrecida y manchada. El sobrino de Melle pensó que traería dos yemas, y se le antojó para el desayuno una torreznada, y cuando ya se encogían los torreznos en la sartén, cascó el huevo en un plato para batirlo, y el huevo por dentro, estaba vacío de clara y yema, y solamente guardaba un sobre, en el que estaba escrito con letra de lápiz de color - letra comprobada del finado Melle- esto: "Arreglad la chimenea. Tu tío que lo es Victoriano Melle". Y bajo el nombre, una solemne rúbrica. Y bien se veía que Melle había mojado la punta del lápiz más de dos veces escribiendo el recado.

Dio la noticia el sobrino a voces, acudieron los vecinos, y fue leído cien veces el sobre. Cuando el sobrino fue al gallinero a buscar la gallina del pescuezo pelado, la encontró muerta. Y el aviso del finado había llegado a tiempo si hubiera sido atendido, que dos noches después un vendaval que venía loco, se llevó la chimenea de los Melle.

Y esto es todo. Los Melle de Loboso conservan la carta del tío. Hay vecinos del lugar que dicen que aun recibieron otras, y todas en huevos o por caminos aun más secretos, pero que estas cartas no las muestran porque tratan de intereses y de consejos en pleitos».

En Loboso, al lado de la vieja casa familiar de Melle, nació mi amigo Primitivo Iglesias, Catedrático de Lengua y Literatura Gallega en Lugo, cunqueiriano de pro y alcalde de Pastoriza en la actualidad. Primitivo hizo allí su casa nueva, donde vive, y antes de empezar su construcción puso a los canteros la única condición de que su nueva casa tendría un metro más de altura que la vecina de Melle. Quienes tenemos el privilegio de gozar de su amistad podemos seguir su sabio consejo y leer el relato de Cunqueiro en la terraza de la nueva casa de Primitivo y, así, observar que todo lo que el texto de Cunqueiro dice de Loboso es la pura verdad, como también lo es la vista real de la vieja casa de Melle, abandonada y con la chimenea derribada sobre un techo en ruinas. Por ello entrar en la magia inmersos en esta realidad se hace una transición natural. Y así ya nos 
parece normal la fantasía cunqueiriana de la nota encontrada en el huevo de una gallina de pescuezo pelado. Porque, con el apoyo de la oralidad y las creencias y supersticiones de quienes la practican en sus narraciones populares, Cunqueiro supo naturalizar muy bien la verosimilitud literaria de sus fantasías en la vida cotidiana. Con razón había dicho alguna vez de estas criaturas suyas que por haberlas estudiado tanto tiempo y tan cerca había podido inventarlas. 
